\title{
\# TNF- $\alpha$ AND ADIPONECTIN PATHWAYS ARE DEREGULATED IN ENDOMETRIA FROM OBESE WOMEN WITH POLYCYSTIC OVARIAN SYNDROME (PCOS)
}

HOSPITAL CLINICOO UNIVERSIDAD DE CHILE

\section{Oróstica L1, Astorga I', García V1,3, Poblete C ${ }^{1}$, Romero C1,2, Vega M1,2}

${ }^{1}$ Laboratory of Endocrinology and Reproductive Biology, ${ }^{2}$ Department of Obstetrics and Gynecology, Clinical Hospital, Faculty of Medicine, University of Chile, Santiago of Chile. ${ }^{3}$ Faculty of Health Sciences, University of Antofagasta, Chile.

\section{OBJECTIVES}

METHODS

STUDIED GROUPS

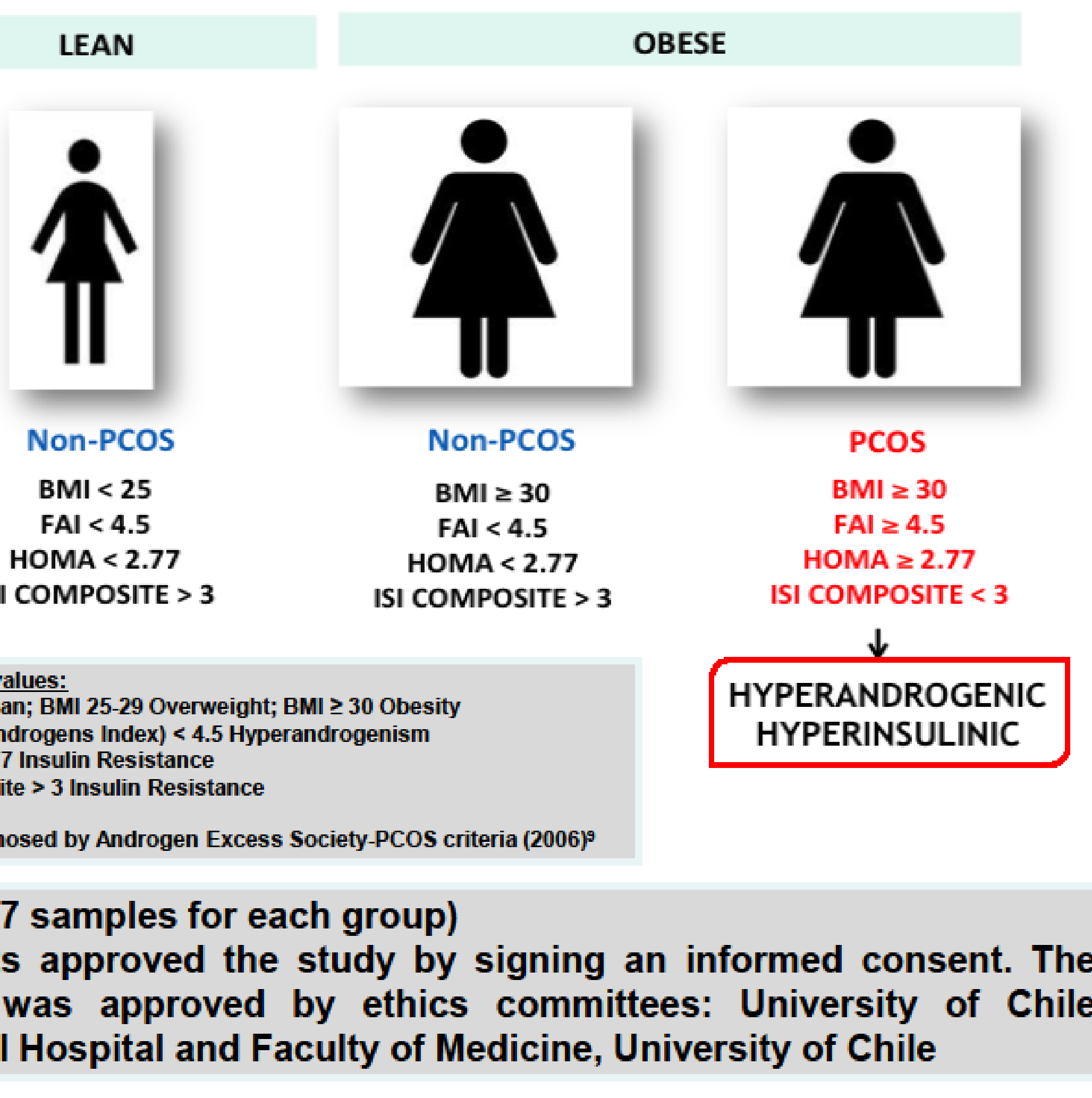

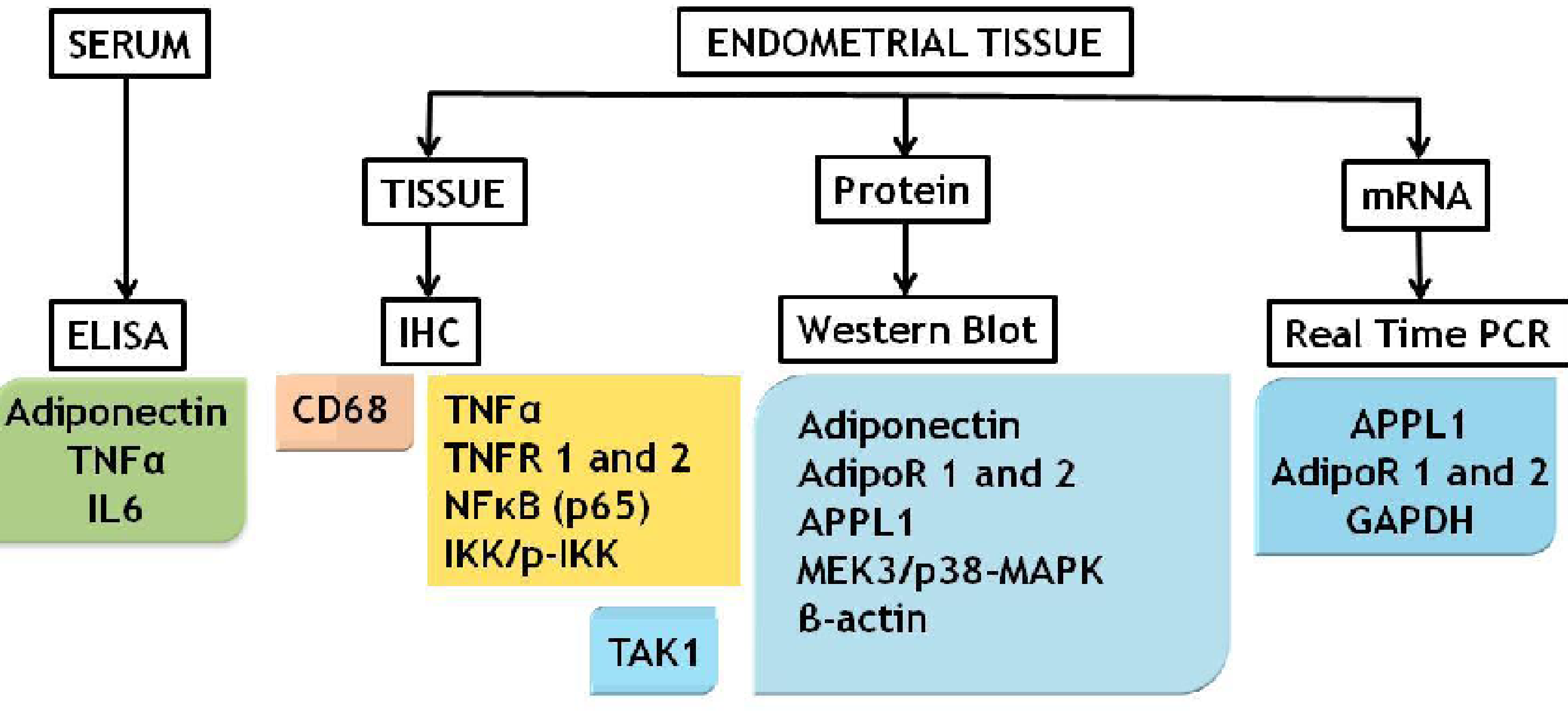

Statistics analysis: Results were analyzed by Mann-Whitney test for comparisons between groups. For multiple comparisons, ANOVA non-parametric: Kruskal-Wallis statistical test followed by Dunn's post-test were used. Different letters indicate
significant differences $(a \neq b \neq c$ with $p<0.05)$. Statistical tests were performed using significant differences $(a \neq b \neq c$ with $p<0.05$ ). Statistical tests were performed using
Graph Pad Prism 5 .

\section{RESULTS}

\subsection{1..1.}
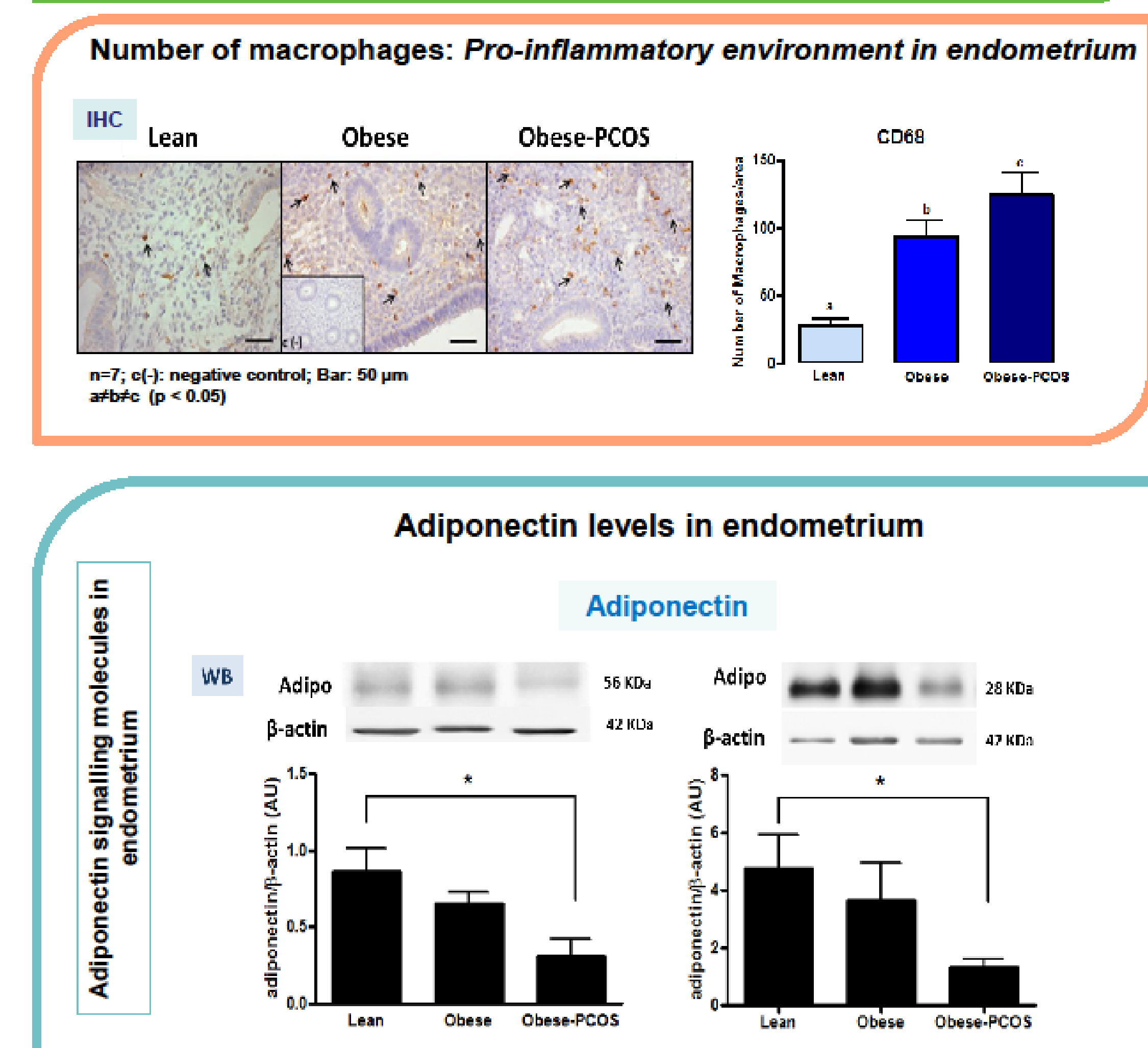

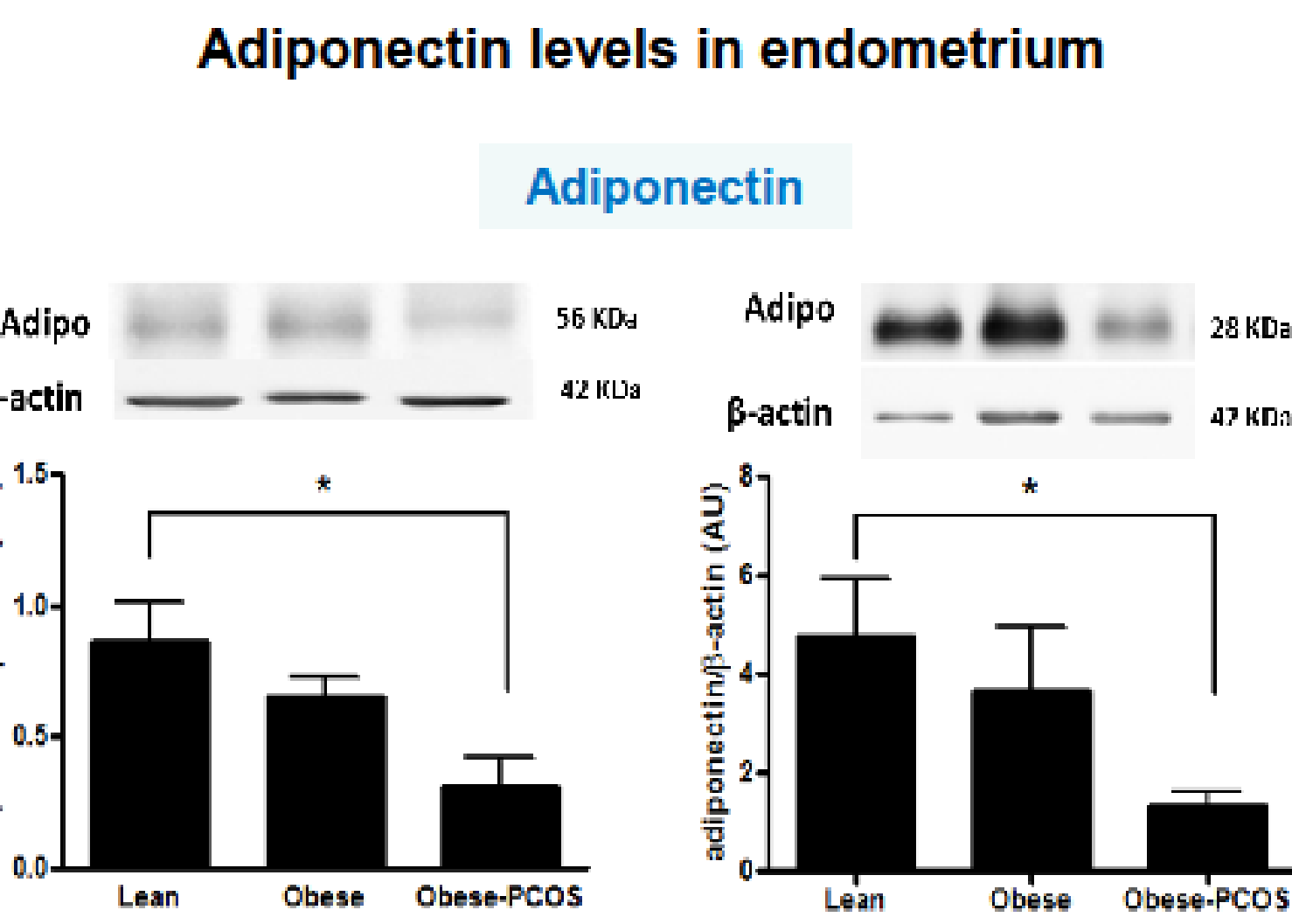

I.
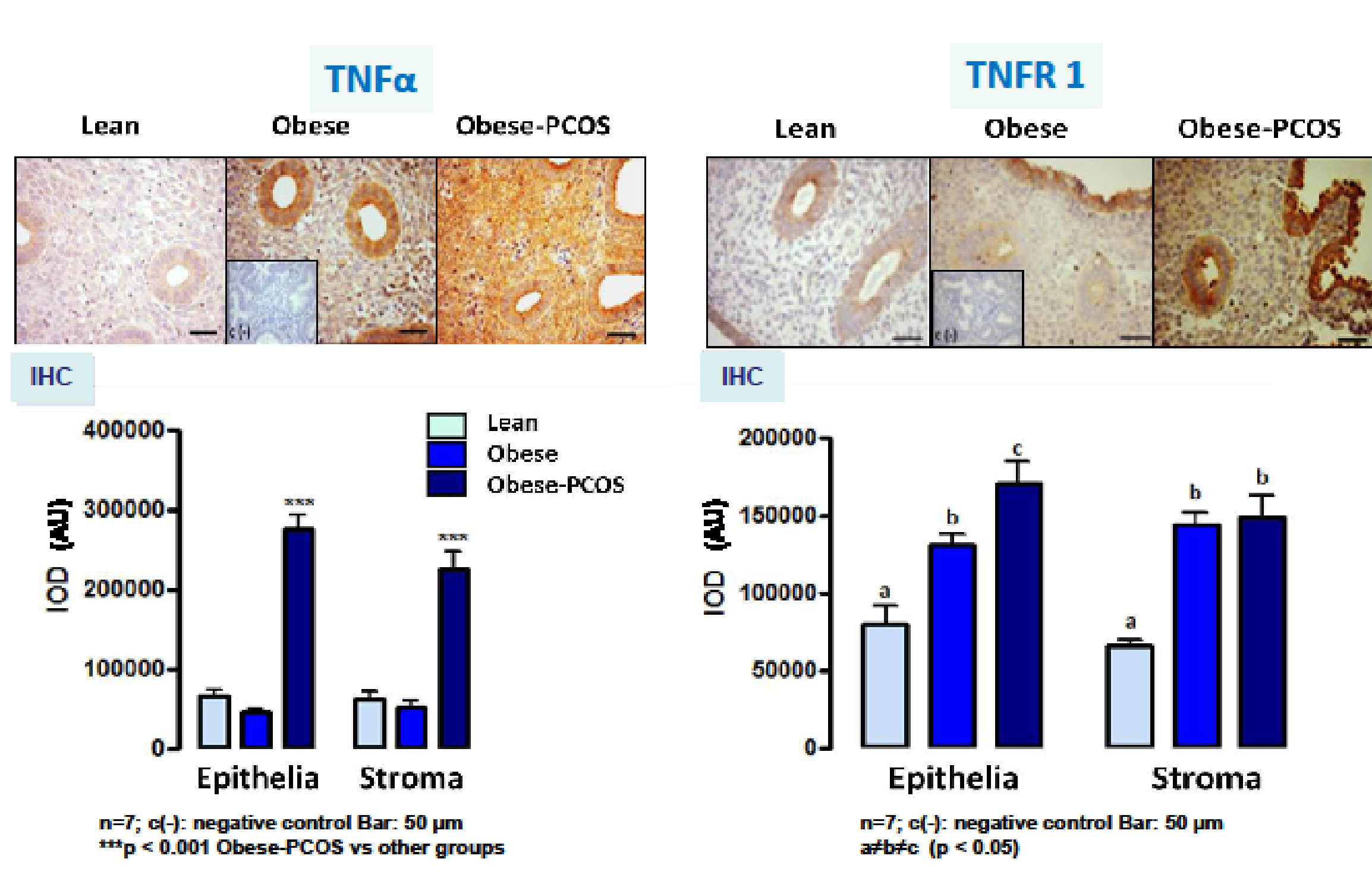

Adiponectin receptors levels in endometrium
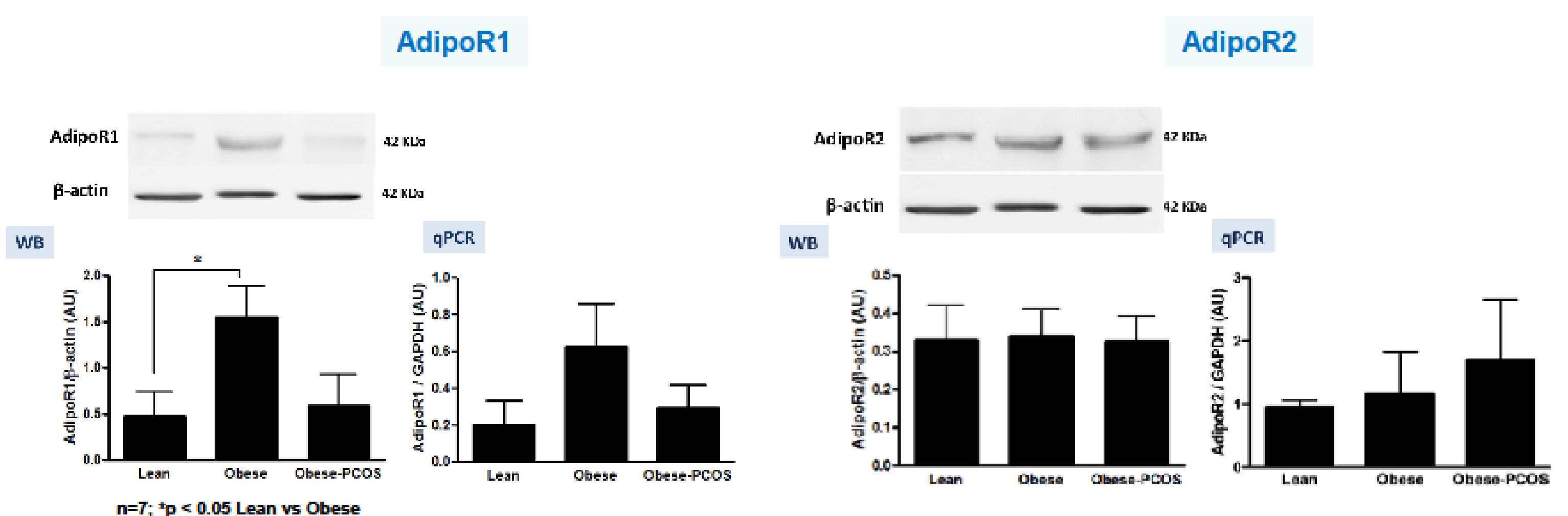

\section{CONCLUSIONS}

\section{In obese women with PCOS:}

Circulating levels of IL6 are higher

Serum and endometrial Adiponectin levels are lower

A

Molecules levels of TNFa signalling pathway are increased in

endometrium, whereas, Adiponectin signalling molecules are

decreased

\section{THEREFORE...}

An increased inflammatory environment in endometrium of Obese-PCOS women was observed. This could decrease Adiponectin signalling through the participation of TNFa, NFKB and/or IL-6, affecting insulin signalling under obesity, hyperandrogenic and hyperinsulinic conditions. Thus, in these conditions the energetic metabolism for norma endometrial function could be compromised.

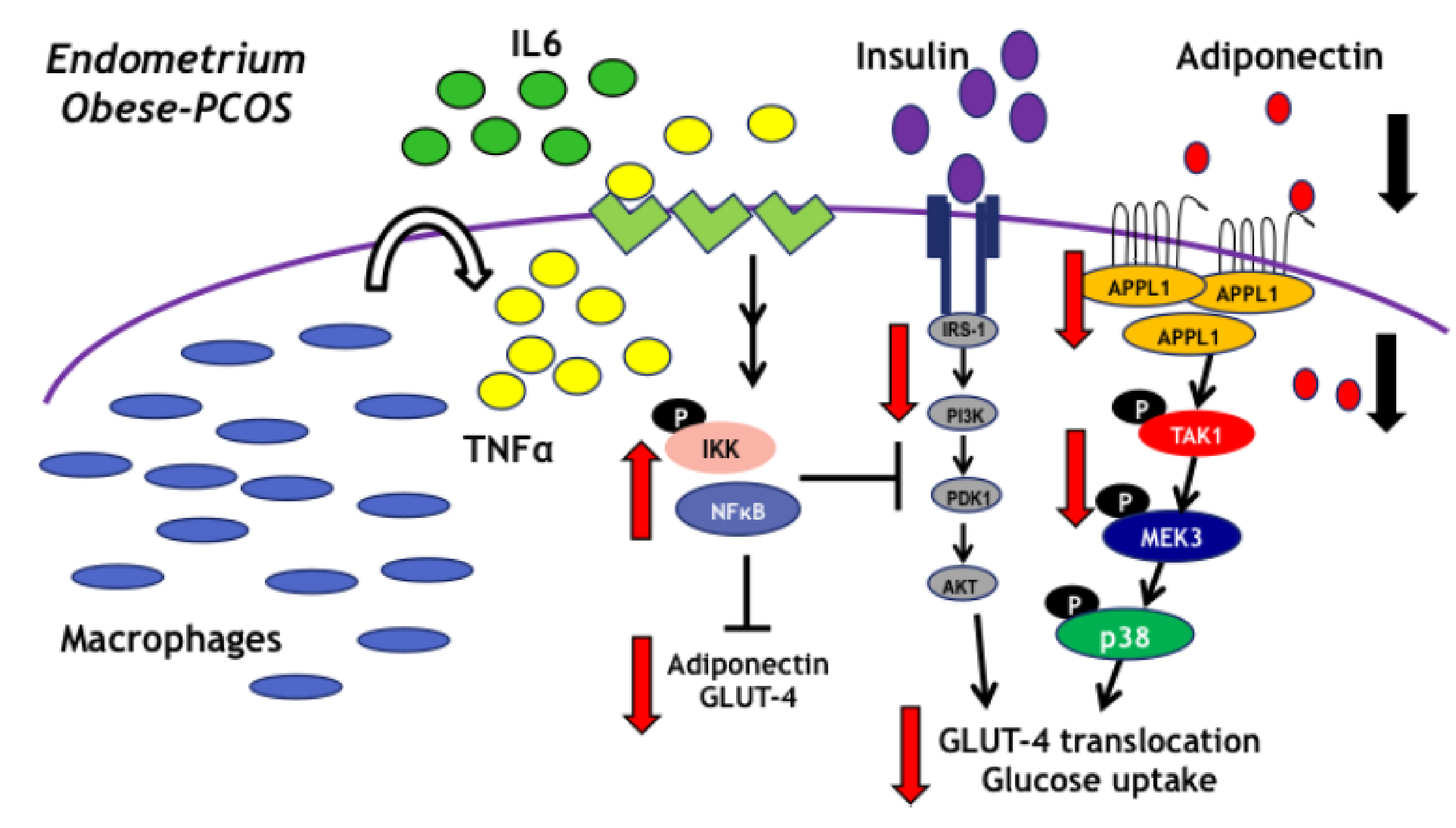

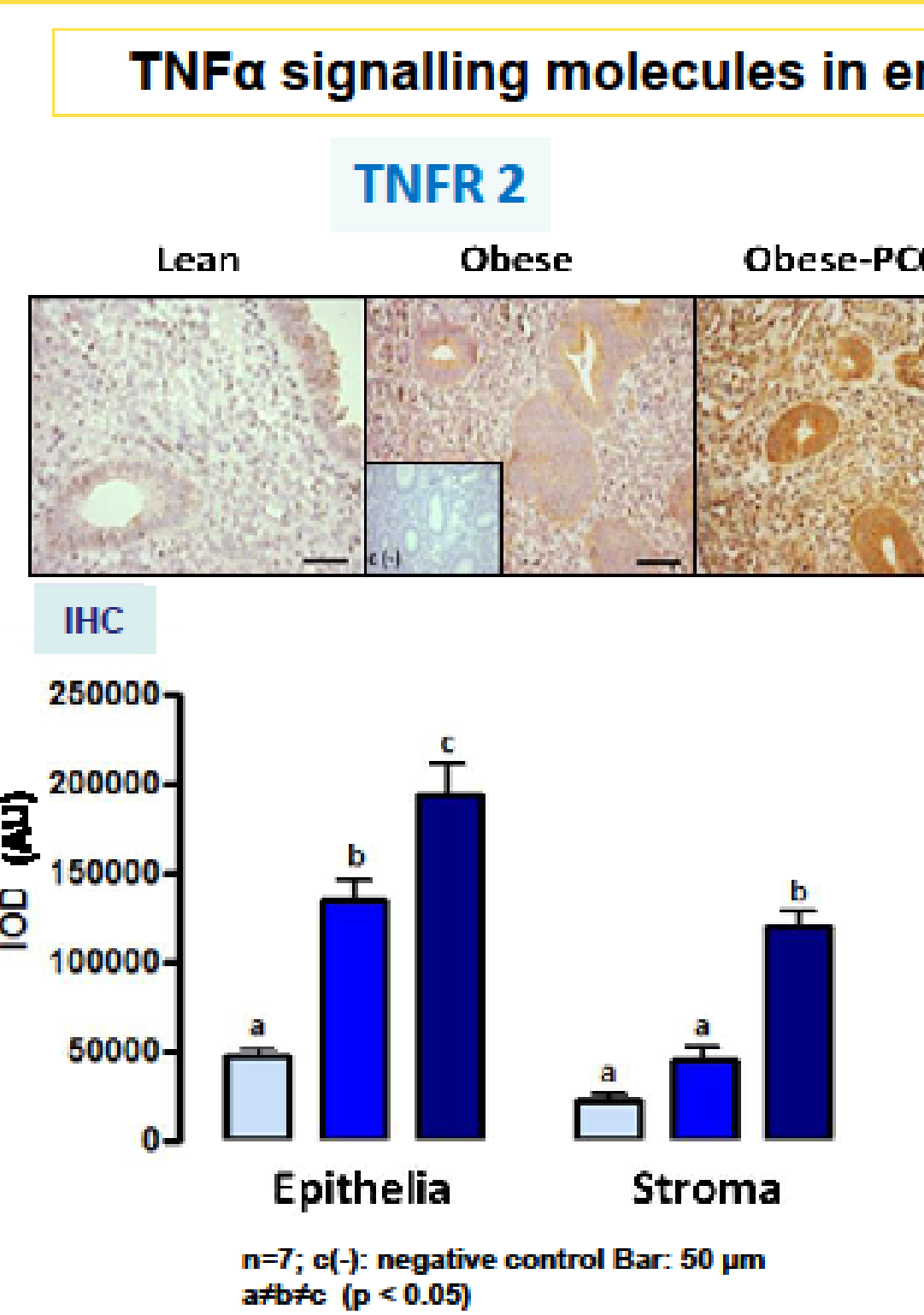
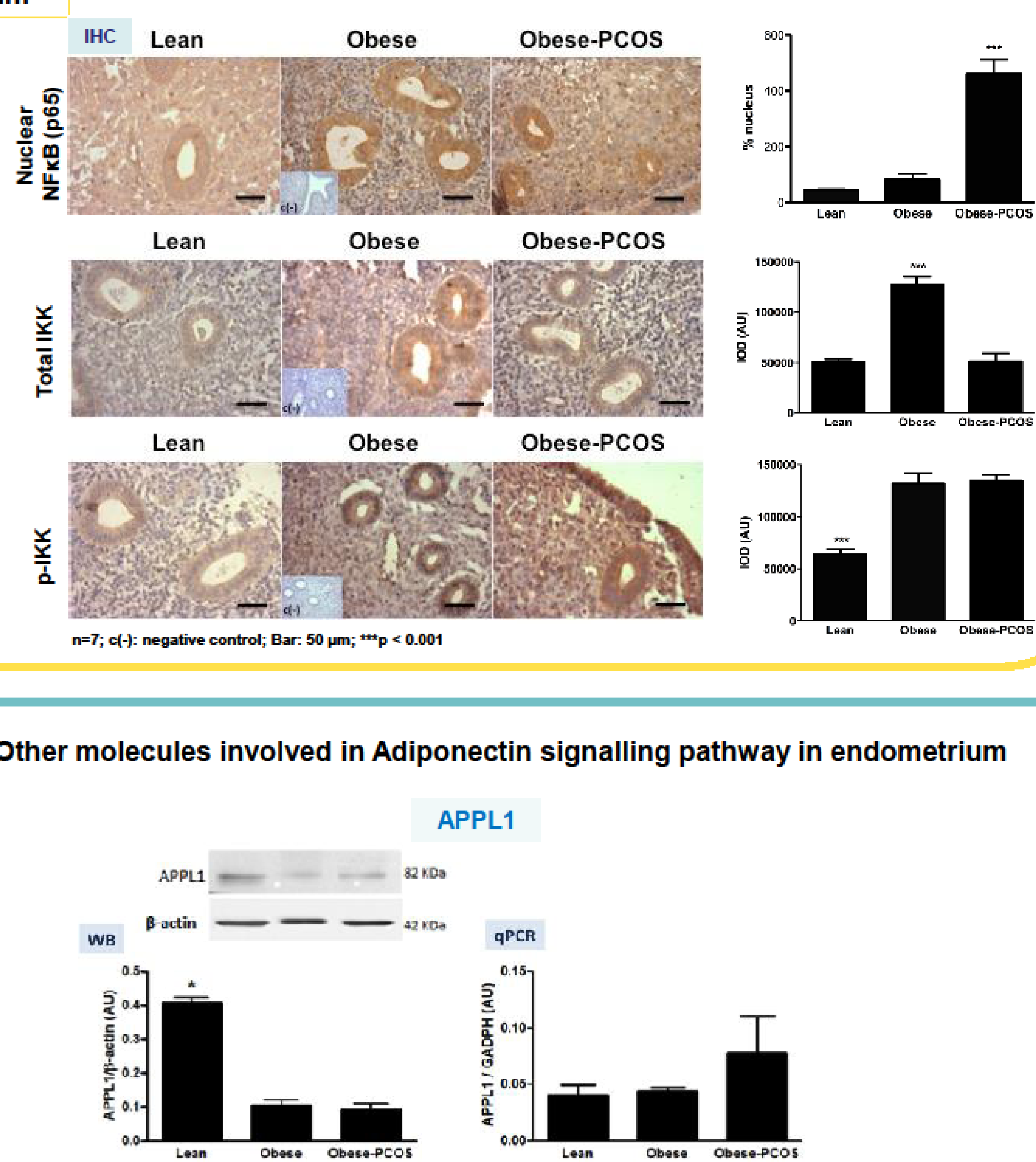

МЕКЗ

p38 MAPK

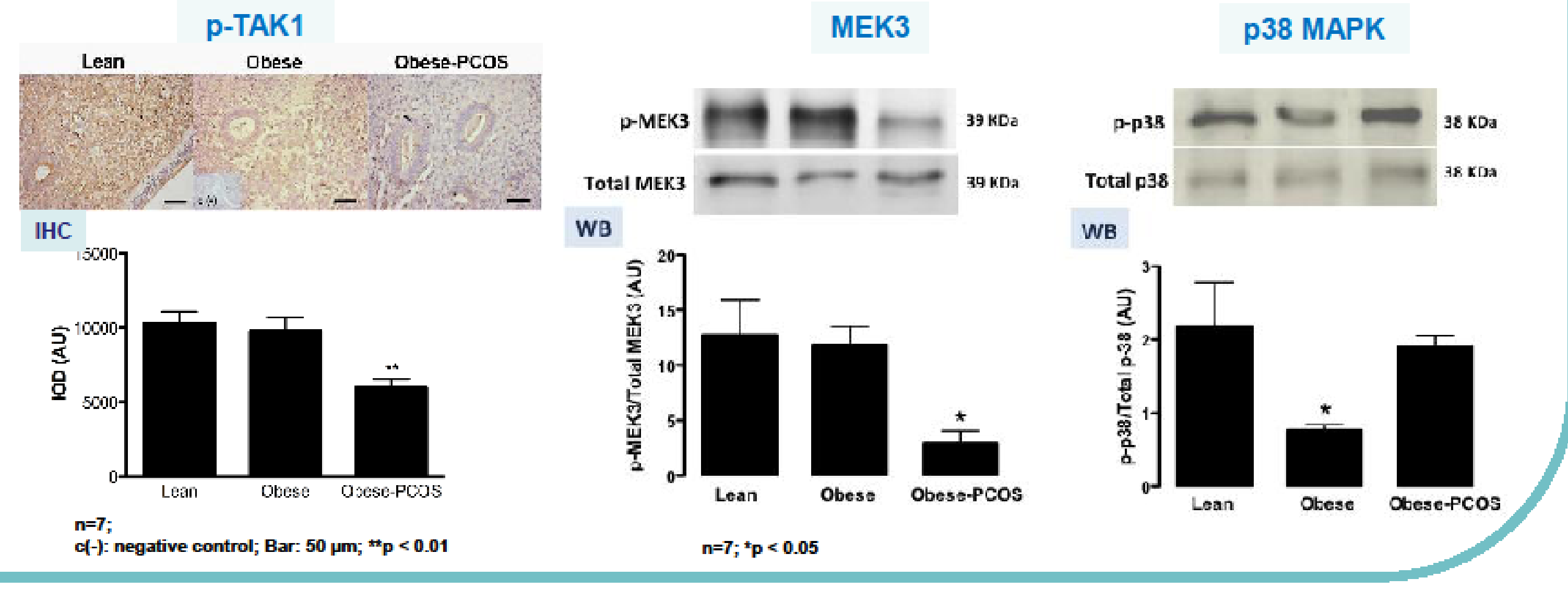

REFERENCES

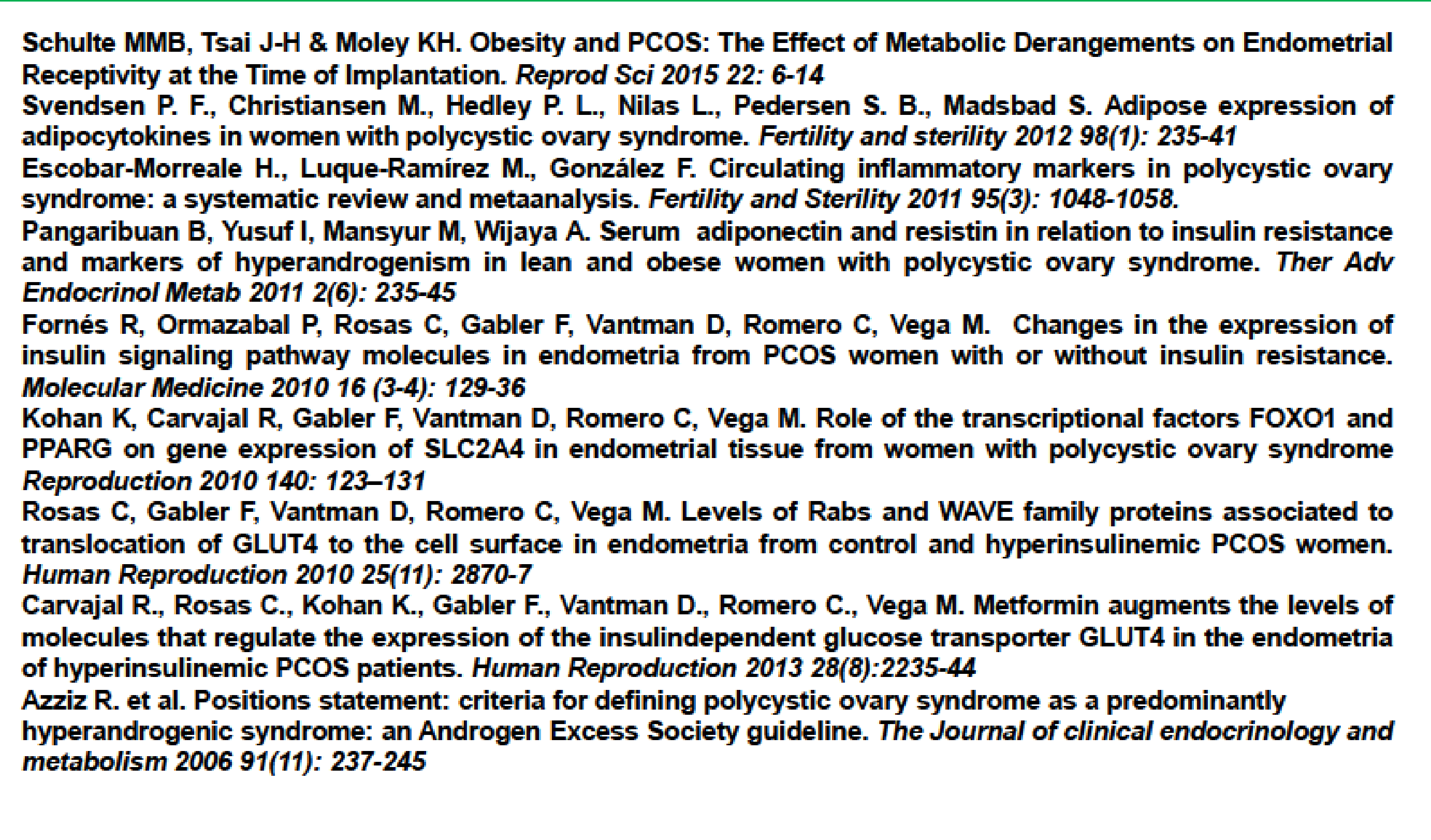

